\title{
The interplay of emotional instability, empathy, and coping on prosocial and aggressive behaviors
}

\author{
Gustavo Carlo $^{\mathrm{a}, *}$, Maria Vicenta Mestre ${ }^{\mathrm{b}}$, Meredith M. McGinley ${ }^{\mathrm{c}}$, Paula Samper ${ }^{\mathrm{b}}$, Ana Tur $^{\mathrm{b}}$, \\ Deanna Sandman ${ }^{\text {a }}$ \\ a Department of Human Development and Family Studies, University of Missouri, Columbia, MO, 65211, USA \\ ${ }^{\mathrm{b}}$ Department of Psychology, University of Valencia, Avenida Blasco Ibanez, 13, Valencia 46010, Spain \\ ${ }^{\mathrm{c}}$ Department of Psychology, Chatham University, Pittsburgh, PA, 15232, USA
}

\section{A R T I C L E I N F O}

\section{Article history:}

Received 12 January 2012

Received in revised form 16 May 2012

Accepted 18 May 2012

Available online 14 June 2012

\section{Keywords:}

Prosocial behaviors

Empathy

Coping

Aggression

Impulsivity

\begin{abstract}
A B S T R A C T
Mediating and moderating effects of socioemotive traits and coping styles on aggression and prosocial behaviors were examined. A sample of 1557 students from Spain $(53 \%$ male, $M$ age $=13.12)$ completed self-report instruments of coping, empathy, emotional instability, physical aggression, and prosocial behaviors. Structural equation analysis showed support for two mediation models but little support for moderation. Emotional instability positively predicted emotion-focused coping, which in turn, positively predicted aggression. In contrast, empathy positively predicted problem-focused coping, which in turn, positively predicted prosocial behaviors. Moreover, problem-focused coping positively predicted trait empathy, which in turn positively predicted prosocial behaviors, and negatively predicted aggression. Emotion-focused coping was positively related to emotional instability, which in turn, was positively related to aggression. Discussion focuses on the interplay of self regulation and socioemotive traits in predicting aggressive and prosocial behaviors.
\end{abstract}

(c) 2012 Elsevier Ltd. All rights reserved.

\section{Introduction}

Aggression (i.e., acts that harm others) and prosocial behaviors (i.e., acts that benefit others) are commonly observed social behaviors that have important health and societal implications (Carlo, 2006; Coie \& Dodge, 1998). Researchers have demonstrated increases in aggressive, and decreases in prosocial, behaviors during adolescence (Carlo, 2006; Pulkinnen \& Pitkanen, 1993). In recent years, research aimed at understanding the mechanisms underlying these social behaviors has increased, though often such research focuses on either aggression or prosocial behaviors, but not both simultaneously. Such investigations have identified a number of antecedent emotion-related variables such as coping (i.e., regulation of emotions and behaviors), emotional instability (i.e., impulsivity), and empathy (i.e., feeling the same as another). However, research has not examined the interplay of coping styles, emotional instability, and empathy in predicting aggressive and prosocial behaviors in adolescents. The present study was designed to address this gap.

There is relative consensus that coping is a multidimensional construct that pertains to cognitive, affective, and behavioral

* Corresponding author. Address: 410 Gentry Hall, University of Missouri, Columbia, MO 65211, USA. Tel. +1 5738846301.

E-mail address: carlog@missouri.edu (G. Carlo). responses to demands and challenges on the individual (Cole, Michel, \& Teti, 1994; Compas, Connor-Smith, Saltzman, Thomsen, \& Wadsworth, 2001; Lazarus \& Folkman, 1984). The cognitive component includes aspects of attentional, encoding, and recall processes, such as attention shifting, attention focusing, and selective recall (Derryberry \& Rothbart, 1988). Affective and physiological arousal processes are also relevant components of coping and reflect individual differences in reactivity to stimuli. Behavioral regulation addresses the gap between cognitive and affective responding and reflects control of behavioral manifestations. According to scholars, individuals display wide but stable, individual differences in coping to stressors that may be temperamentally based (Compas et al., 2001; Derryberry \& Rothbart, 1988; Lazarus \& Folkman, 1984).

One common approach is to categorize coping into two broad types, problem-focused and emotion-focused (Carver \& Scheier, 1994; Compas et al., 2001; Frydenberg \& Lewis, 1996; Pastorelli, Barbaranelli, Cermak, Rozsa, \& Caprara, 1997). Problem-focused or productive coping refers to responses aimed at reducing or eliminating the source of the stress, and includes problem solving, planfulness, and instrumental support-seeking. In contrast, emotion-focused or nonproductive coping (including venting, distraction, avoidance) is defined as responses aimed at improving one's psychological or emotional state. Interestingly, direct research on the relations between these forms of coping and 
prosocial and aggressive behaviors is virtually nonexistent, especially in adolescence. However, research exists on the links between different forms of coping and aggressive and prosocial behaviors, especially in childhood (e.g., Eisenberg, Fabes, \& Spinrad, 2006; Rothbart, Ahadi, \& Hershey, 1994; see Coie \& Dodge, 1998). Such research generally demonstrates that more effective coping (such as problem focused) is positively associated with prosocial behaviors and negatively related to aggression, whereas less effective coping (such as emotion focused) is positively related to aggression and negatively related to prosocial outcomes (see Compas et al., 2001; Eisenberg et al., 2006). However, these relations can differ depending upon situational factors (such as the controllability in the situation) and one form of coping does not preclude the use of other forms (Cheng, 2001).

Socioemotive traits such as emotional instability and empathy, have also been closely tied to social behavioral outcomes. Emotional instability is usually characterized as a tendency to exhibit rapid, unexpected, and intense affective reactions. The presence of emotion dysregulation and intense emotional responding that are cardinal features of emotional instability likely leads to proneness for aggressive tendencies and difficulties in prosocial behaviors., In general, emotional instability (similar to impulsivity; Buss \& Plomin, 1975) has been associated with high levels of aggression, conduct disorder problems and borderline personality(Caprara \& Pastorelli, 1993; Cole, Llera, \& Pemberton, 2009; Cooper, Wood, Orcutt, \& Albino, 2003; Koenigsberg, 2010; Leech, Day, Richardson, \& Goldschmidt, 2003; Martino, Ellickson, Klein, McCaffrey, \& Edelen, 2008; Pastorelli et al., 1997). However, to our knowledge, the direct relations between impulsivity and prosocial behaviors have not been studied.

Empathy usually requires good coping and self regulation skills (Eisenberg \& Fabes, 1992). Hoffman (2000) noted that empathy requires moderate levels of arousal such that the individual can attend to the needs of others and is motivated to act in ways that benefit needy others. On the other hand, proneness to overarousal might result in personal distress (i.e., a self-focused, aversive affective reaction) and consequently, reduced levels of empathy and prosocial behaviors. There is substantive evidence on the positive relations between empathy and prosocial behaviors, and negative relations to aggression (Eisenberg et al., 2006).

Conceptually, scholars have proposed different models on the links among traits, coping, and outcomes. One proposal is that, because personality characteristics reflect relatively enduring, stable, biologically-based traits, socioemotive traits such as emotional instability and empathy may predict coping, which in turn, may predict behavioral outcomes, and there is substantial supportive evidence (Bolger, 1990; Bolger \& Zuckerman, 1995; Vollrath, 2001). Therefore, one would expect that emotional instability might positively predict emotion-focused coping and aggressive behaviors, and negatively predict problem-focused coping and prosocial behaviors. In contrast, empathy might positively predict problem-focused coping and prosocial behaviors, and negatively predict emotion-focused coping and aggressive behaviors.

Alternatively, developmental scholars assert that trait coping are also relatively enduring and stable and reflect aspects of temperament (Derryberry \& Rothbart, 1988; Eisenberg \& Fabes, 1992). Because problem-focused coping is an other-oriented tendency that reflects moderate arousal tendencies, and these are defining characteristics of empathic and prosocial tendencies, one might expect such coping to facilitate prosocial tendencies. In contrast, individuals with emotion-focused coping styles might be prone to emotional instability and aggressive behaviors. Thus, an alternative model is that these emotion-related traits might mediate the relations between coping styles and social behaviors. Some researchers have found support for the notion that socioemotive traits mediate the relations between coping and outcomes (Vollrath, Alnaes, \& Torgersen, 1998; Woodward, Murrell, \& Bettler, 2005). Furthermore, research shows that coping interventions predict changes in socioemotive traits (such as empathy and impulsivity; e.g., Hofmann, Grossman, \& Hinton, 2011; Sever, Guttmann, \& Lazar, 2007). However, direct evidence on the possible mediating roles of empathy and emotional instability is sparse.

Although mediating relations are possible, some researchers have reported and found evidence that personality and coping might interact to predict outcomes (Bolger \& Schilling, 1991; Bolger \& Zuckerman, 1995; Roesch, Aldridge, Vickers, \& Helvig, 2009). For example, traits might be differentially related to social behaviors as a function of levels of coping. Specifically, one might expect that emotional instability might be positively related to aggressive behaviors, and negatively related to prosocial behaviors, only at high levels of emotion-focused coping or low levels of problem-focused coping. Similarly, empathy might be negatively related to aggressive behaviors, and positively related to prosocial behaviors, only at high levels of problem-focused coping or at low levels of emotion-focused coping. Thus, we also tested whether the effects of emotional instability and empathy are exacerbated only at high or low levels of the presence of coping.

\section{Method}

\subsection{Participants and procedure}

The sample was 1557 students (53\% male, $M$ age $=13.12$, $S D=.87$; range $=12-15$ years) from Valencia, Spain. The sample was recruited to include a broad distribution of students from schools that have more than $30 \%$ immigrant children in classes, between $20 \%$ and $30 \%$, or less than $20 \%$. Distribution in mothers' education was relatively equal (38\% less than high school diploma, $27 \%$ high school diploma, $23 \%$ at least some university education). The majority of the sample self-identified from Spain (83\%; $10 \%$ from Latin America and 4\% from Eastern European countries). Trained experimenters administered the surveys in classrooms, which took approximately $45 \mathrm{~min}$ to complete.

\subsection{Measures}

Each of the measures administered have been adapted for use and validated in samples of adolescents from Spain (e.g., Del Barrio, Moreno, \& Lopez, 2001; Mestre, Pérez, Frías, \& Samper, 1999; Pereña \& Seisdedos, 1997). However, initial results from a full structural equation model (see below) indicated that these measures may be multidimensional. Thus, exploratory factor analysis (EFA) was conducted for each of these measures (with the exception of coping, see below) in Mplus 6.1 (Muthén \& Muthén, 1998-2010).

\subsection{Empathy}

The Inventory of Empathy for Children and Adolescents (Bryant, 1982; Mestre et al., 1999) was used to assess their tendency to feel sorrow or concern for others. Adolescents responded to 15 items on a yes/no scale. As the initial confirmatory factory analysis (CFA) indicated the overall model did not fit the data well, an EFA was conducted and revealed that a 4-factor model fit the data well, and one factor emerged as the factor which best adhered to our definition of empathy. A CFA suggested that this 6-item (e.g., "I get upset when I see a girl being hurt"; $\alpha=.70$ )factor fit the data well $\left(\chi^{2}(5)=25.37, p<.01, \mathrm{CFI}=1.00\right.$, RMSEA $\left.=.05\right)$. 


\subsection{Prosocial behaviors, aggression, emotional instability}

A multidimensional instrument (Caprara \& Pastorelli, 1993; Del Barrio et al., 2001) was used to assess prosocial behaviors, physical aggression, and emotional instability. Adolescents responded to these items on a 3-point scale, anchored by 1 (Never) to 3 (Frequently). The original 10 -item scale for prosocial behavior fit the data well after conducting an initial CFA, but one multivocal item was dropped. The final 9-item scale (e.g., "I console those who are sad"; $\alpha=.70)$ fit the data well $\left(\chi^{2}(23)=91.35, p<.01\right.$, $\mathrm{CFI}=.96$, RMSEA $=.04$ ).

Conversely, physical aggression did not fit the data well initially. An EFA suggested two factors, and we selected the factor representing physical aggression. The CFA for the seven physical aggression items (e.g., "I kick and punch others") fit the data well, but one item was dropped in the full model after modification indices suggested that this item was multivocal. The final 6-item physical aggression scale $(\alpha=.76)$ fit the data well $\left(\chi^{2}(14)=51.72, p<.01\right.$, CFI $=.98$, RMSEA =.04). Similarly, the initial CFA for emotional instability did not fit the data well. We selected the EFA factor defined by 5 items tapping into impulsivity (e.g., "I am impatient"). After dropping a multivocal item, the CFA for 4-item emotional instability scale $(\alpha=.62)$ fit the data well $\left(\chi^{2}(2)=9.77, p=.007\right.$, CFI $=.99$, RMSEA $=.05$ ).

\subsection{Problem and emotion-focused coping}

Items from the ACS (Frydenberg \& Lewis, 1996; Pereña \& Seisdedos, 1997) that tap into problem-focused (productive; e.g., help seeking, problem solving) and emotion-focused (nonproductive; e.g., avoidance, rumination) coping were selected. After dropping several multivocal items, 8 problem-focused coping items $(\alpha=.74)$ and 13 emotion-focused coping items ( $\alpha=.79)$ were identified. A CFA fitting both of these final coping factors fit the data acceptably $\left(\chi^{2}(196)=581.71, p<.01, \mathrm{CFI}=.92, \mathrm{RMSEA}=.04\right)$.

\subsection{Data analysis plan}

In order to examine the direct and indirect relations among these latent variables, path models were tested using full structural equation modeling in Mplus 6.1 (Muthén \& Muthén, 1998-2010). Model fit was considered good if the Comparative Fit Index (CFI) is approximately .95, or the Root Mean Square Error of Approximation (RMSEA) is less than or equal to .06 (Hu \& Bentler, 1999). All reported model parameters (i.e., path coefficients) were statistically significant at the .05 level.

In order to test the trait coping mediation model, the latent physical aggression and prosocial behavior factors were regressed onto the latent coping mediators (problem-focused and emotionfocused coping)as well as onto the distal latent predictors(emotional instability and empathy). Additionally, the mediators were also regressed onto both emotional instability and empathy. Gender, age, and parents' education were controlled for in the model. The bootstrap procedure $(N=1000)$ was implemented in Mplus6.1 in order to determine whether the indirect effects were statistically significant. An indirect effect was significant if the $95 \%$ confidence interval for the standard error estimate fell outside of zero (MacKinnon, Lockwood, Hoffman, West, \& Sheets, 2002). Additionally, the full information maximum likelihood estimator was requested in Mplus in order to estimate any missing data. A similar procedure was used to test the sociocognitive trait mediation model in which emotional instability and empathy were considered mediators of the relations between coping styles and outcomes. Finally, four separate moderation model tests were conducted to examine the interactions between either problem- or emotion-focused coping and either emotional instability and empathy, as they related to both prosocial behaviors and physical aggression (we also regressed these two outcomes onto the corresponding main effects). We used the $\mathrm{x}$ with command in Mplus 6.1 in order to test for this latent variable interaction. If the interaction was significant, we used the latent factor scores to create two equal groups to examine the relation between predictor and the outcome for these two groups (e.g., low and high empathy).

\section{Results}

\subsection{Main model results}

Univariate statistics and correlations can be found in Table 1. The coping mediation model (Fig. 1) had acceptable fit to the data $\left(\chi^{2}=2324.500(1052), p<.01, \mathrm{CFI}=.92\right.$, RMSEA $\left.=.03\right)$. The fit indices provided here are from the analysis without the bootstrap option, as fit indices are not provided in the bootstrapped analysis. Standard errors from the bootstrapped analysis, however, are reported. Prosocial behaviors were positively predicted by empathy and problem-focused coping, whereas physically aggressive behaviors were positively predicted by emotional instability and emotion-focused coping, and negatively predicted by empathy. Problem-focused coping was positively predicted by empathy, and emotion-focused coping was positively predicted by emotional instability. Two indirect effects were significant (see Table 2): (1) empathy was related to prosocial behaviors via problem-focused coping, and (2) emotional instability was only related to physically aggressive behaviors via emotion-focused coping. These mediational paths respectively accounted for $25 \%$ and $10 \%$ of the variance

Table 1

Means, Standard Deviations, Correlations for the Main Study Variables.

\begin{tabular}{|c|c|c|c|c|c|c|c|c|c|}
\hline Variable & 1 & 2 & 3 & 4 & 5 & 6 & 7 & 8 & 9 \\
\hline 1. Emotion-focused coping & - & & & & & & & & \\
\hline 2. Problem-focused coping & -.05 & - & & & & & & & \\
\hline 3 Emotional instability & $.14^{* *}$ & .01 & - & & & & & & \\
\hline 4. Empathy & -.06 & $.17^{* *}$ & $-.07^{* *}$ & - & & & & & \\
\hline 5. Physical aggression & $.21^{* *}$ & $-.11^{* *}$ & $.34^{* *}$ & $-.21^{* *}$ & - & & & & \\
\hline 6. Prosocial Behavior & $-.13^{* *}$ & $.28^{* *}$ & -.04 & $.40^{* *}$ & $-.24^{* *}$ & - & & & \\
\hline 7. $\operatorname{Sex}^{\mathrm{a}}$ & $-.16^{* *}$ & $.08^{* *}$ & .01 & $.35^{* *}$ & $-.25^{* *}$ & $.27^{* *}$ & - & & \\
\hline 8. Age & .04 & -.04 & .02 & -.02 & $.08^{* *}$ & $-.07^{* *}$ & $-.10^{* *}$ & - & \\
\hline 9. Parents' education & -.04 & $.17^{* *}$ & $-.06^{*}$ & .05 & $-.10^{* *}$ & $.18^{* *}$ & .03 & $-.15^{* *}$ & - \\
\hline Mean & 2.07 & 3.32 & 2.02 & 3.88 & 1.37 & 2.43 & 1.47 & 13.12 & 2.73 \\
\hline SD & .61 & .70 & .44 & 1.60 & .38 & .31 & .50 & .87 & .82 \\
\hline
\end{tabular}

$p<.05$.

* $p<.01$.

a Sex is coded as $0=$ Male, $1=$ Female. 


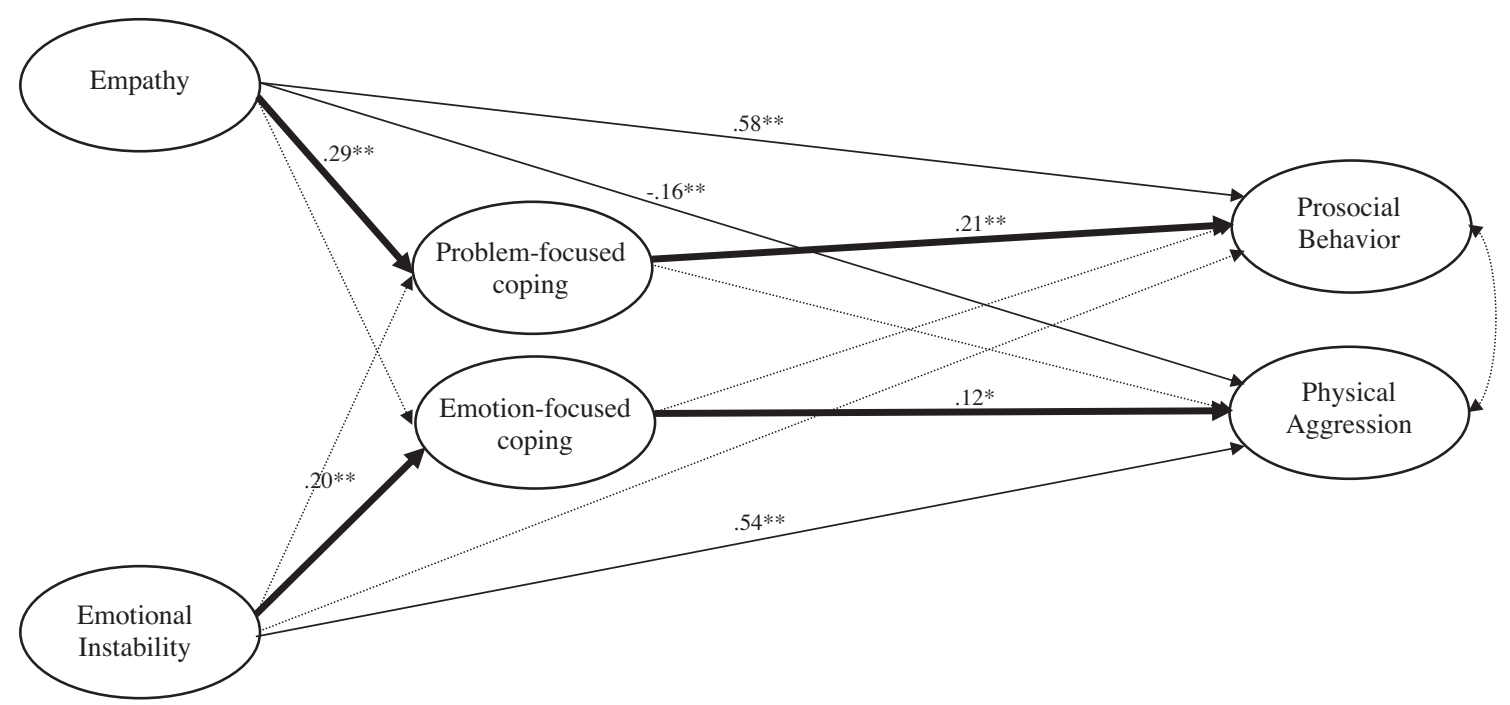

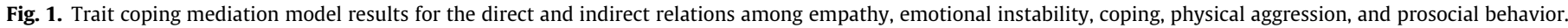
Note. Standardized coefficients are presented. Bold lines indicate a significant indirect effect, and dashed lines represented a nonsignificant path. ${ }^{*} p<.05,{ }^{* *} p<.01$.

Table 2

Indirect Effects (Unstandardized Values) for the Trait Coping and the Sociocognitive Trait Mediation Model.

\begin{tabular}{|c|c|c|c|}
\hline Indirect Effect & Effect & Standard Error & 95\% Confidence Interval \\
\hline \multicolumn{4}{|l|}{ Trait Coping Mediation Model (Fig. 1) } \\
\hline Emotional Instability $\rightarrow$ Emotion-focused Coping $\rightarrow$ Prosocial Behavior & -.025 & .020 & $-.063, .014$ \\
\hline Emotional Instability $\rightarrow$ Emotion-focused Coping $\rightarrow$ Physical Aggression & $.056^{* *}$ & .023 & $.010, .102$ \\
\hline Empathy $\rightarrow$ Emotion-focused Coping $\rightarrow$ Prosocial Behavior & .002 & .002 & $-.002, .006$ \\
\hline Empathy $\rightarrow$ Emotion-focused Coping $\rightarrow$ Physical Aggression & -.004 & .004 & $-.012, .004$ \\
\hline Emotional Instability $\rightarrow$ Problem-focused Coping $\rightarrow$ Prosocial Behavior & .009 & .020 & $-.031, .049$ \\
\hline Emotional Instability $\rightarrow$ Problem-focused Coping $\rightarrow$ Physical Aggression & -.002 & .008 & $-.016, .013$ \\
\hline Empathy $\rightarrow$ Problem-focused Coping $\rightarrow$ Prosocial Behavior & $.027^{*}$ & .007 & $.013, .040$ \\
\hline Empathy $\rightarrow$ Problem-focused Coping $\rightarrow$ Physical Aggression & -.005 & .007 & $-.019, .009$ \\
\hline \multicolumn{4}{|l|}{ Sociocognitive Trait Mediation Model (Fig. 2) } \\
\hline Emotion-focused Coping $\rightarrow$ Emotional Instability $\rightarrow$ Prosocial Behavior & -.008 & .010 & $-.013, .008$ \\
\hline Emotion-focused Coping $\rightarrow$ Emotional Instability $\rightarrow$ Physical Aggression & $.080^{* *}$ & .023 & $.035, .124$ \\
\hline Emotion-focused Coping $\rightarrow$ Empathy $\rightarrow$ Prosocial Behavior & -.042 & .027 & $-.052, .007$ \\
\hline Emotion-focused Coping $\rightarrow$ Empathy $\rightarrow$ Physical Aggression & .008 & .006 & $-.003, .019$ \\
\hline Problem-focused Coping $\rightarrow$ Emotional Instability $\rightarrow$ Prosocial Behavior & .000 & .013 & $-.003, .003$ \\
\hline Problem-focused Coping $\rightarrow$ Emotional Instability $\rightarrow$ Physical Aggression & -.008 & .027 & $-.042, .031$ \\
\hline Problem-focused Coping $\rightarrow$ Empathy $\rightarrow$ Prosocial Behavior & $.152^{* *}$ & .027 & $.046, .116$ \\
\hline Problem-focused Coping $\rightarrow$ Empathy $\rightarrow$ Physical Aggression & $-.042^{*}$ & .027 & $-.052,-.005$ \\
\hline
\end{tabular}

${ }^{*} p<.05$.

$p<.01$.

in each outcome common to both the distal and mediator predictors (i.e., jointly, but not one alone; Preacher \& Kelley, 2011).

The trait mediation model (Fig. 2 ) also had acceptable fit to the data $\left(\chi^{2}=2324.500(1052), p<.01\right.$, CFI $=.92$, RMSEA $\left.=.03\right)$. Results were comparable to the first model results in regards to path loadings among all constructs, except that empathy was only positively predicted by problem-focused coping, and emotional stability was only positively predicted by emotion-focused coping. However, three indirect effects were now significant (see Table 2): (1) problem-focused coping was related to both prosocial behaviors and (2) physically aggressive behaviors via empathy, and (3) emotionfocused coping was only related to physically aggressive behaviors via emotional instability. These mediational paths respectively accounted for $31 \%, 3 \%$, and $10 \%$ of the variance in each outcome common to both the distal and mediator predictors (Preacher \& Kelley, 2011).

\subsection{Moderation results}

Moderation analyses examining the latent variable interaction between emotional instability and emotion-focused coping did not converge. Among the remaining three models, only the latent emotional instability $\times$ problem-focused coping interaction significantly predicted physical aggression $(p=.003)$. Follow-up analyses revealed that the relation between problem-focused coping and physical aggression was positive for those below the mean on emotional instability (unstandardized/standardized path loading $=.033 / .16, p=.02$ ), and negative for those above the mean on emotional instability (unstandardized/standardized path loading $=-.16 /-.25, p<.01)$.

\section{Discussion}

Overall, there was relatively stronger evidence for the mediating roles of both coping and socioemotive traits in predicting behavioral outcomes than in the moderating roles of coping styles or socioemotive traits. In addition, problem-focused coping was generally associated with higher levels of empathy and prosocial behaviors, and lower levels of emotional instability and aggression. In contrast, emotion-focused coping was related to lower levels of empathy and prosocial behaviors, and higher levels of emotional 


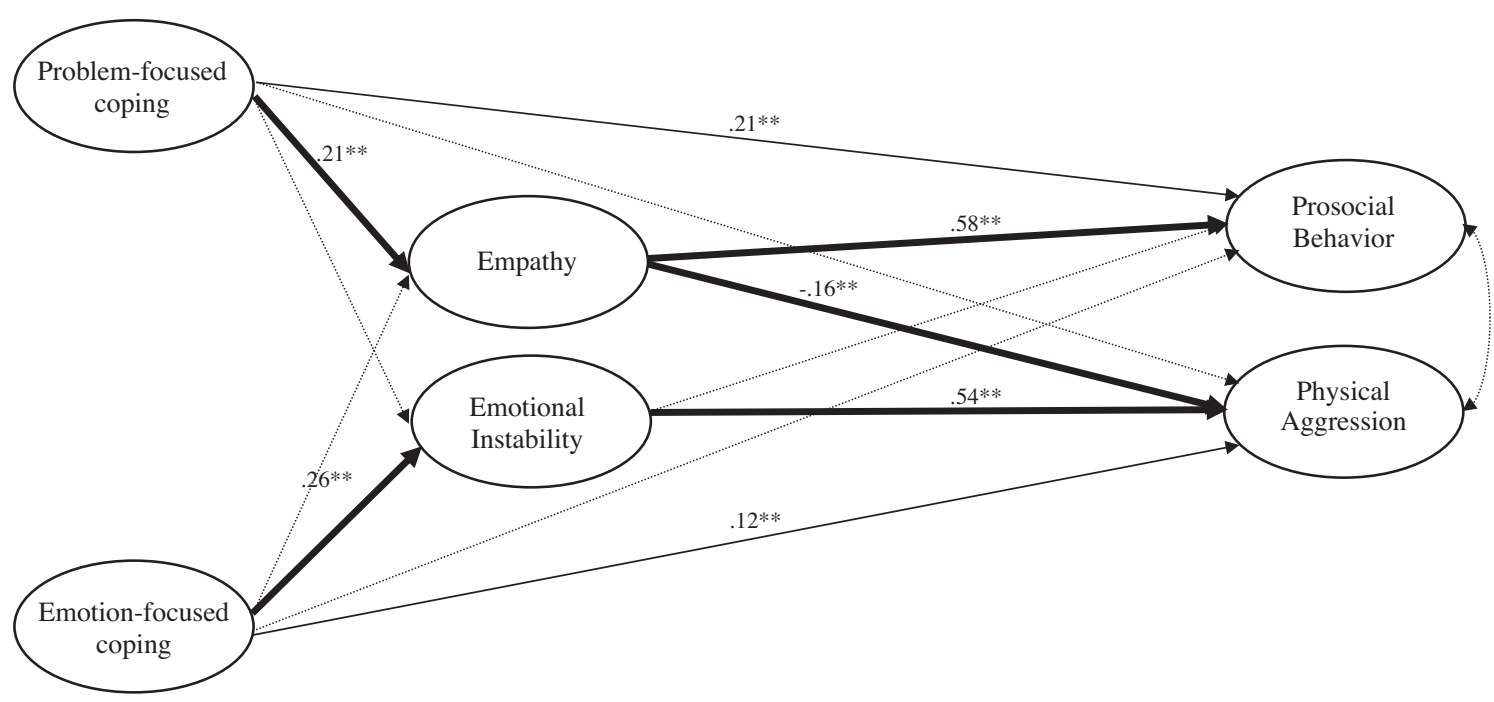

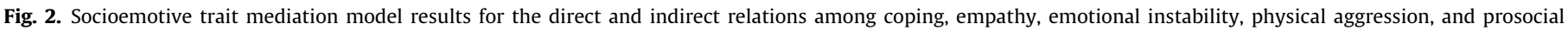
behavior. Note. Standardized coefficients are presented. Bold lines indicate a significant indirect effect, and dashed lines represented a nonsignificant path. ${ }^{* *} p<.01$.

instability and aggression. The findings provide support for the interplay of coping styles and socioemotive traits in understanding aggressive and prosocial behaviors.

Consistent with prior research, the pattern of findings showed that coping may serve as a mediator of the relations between traits and behavioral outcomes. Emotional instability positively predicted emotion-focused coping, which in turn, positively predicted aggression. In contrast, empathy positively predicted problemfocused coping, which in turn, positively predicted prosocial behaviors. Prior scholars have demonstrated the protective and risk enhancing qualities of coping styles but most existing research has been conducted with younger children rather than adolescents. Given previous research that suggests that parents play an important socializing role in the development of children and adolescents' coping (e.g., Kliewer, Fearnow, \& Miller, 1996; Samper, Tur, Mestre, \& Cortés, 2008) and the promise of intervention programs that focus on fostering good coping skills (e.g., Short, Roosa, Sandler, \& Ayers, 1995), the present findings suggest that coping intervention programs could result in positive behavioral outcomes for adolescents with existing individual differences in socioemotive traits.

There was also evidence that the relations between trait coping and behavioral outcomes might be mediated by empathy and emotional instability traits. Problem-focused coping positively predicted trait empathy, which in turn positively predicted prosocial behaviors, and negatively predicted aggression. Emotion-focused coping was positively related to emotional instability, which in turn, was positively related to aggression. These findings are consistent with a relative small research literature suggesting that personality might mediate the relations between coping and outcomes (e.g., Vollrath et al., 1998) and that trait empathy and impulsivity can change by training individuals to develop more effective coping skills (e.g., Sever et al., 2007).

Interestingly, there was relative little evidence for moderation effects (cf. Bolger, 1990). We did find that problem-focused coping was positively linked to aggression when individuals were lower on emotional instability, but negatively linked to aggression when higher on emotional instability. These findings provide suggestive evidence that problem-focused coping may be more effective at mitigating aggressive tendencies for individuals with emotional instability difficulties. However, the finding that problem-focused coping might place adolescents at higher risk for aggression when they are relatively low on emotional instability is somewhat surprising. Perhaps the use of problem-focused coping may be inappropriate in some circumstances (e.g., situations that are out of their control) if adolescents are relatively emotionally stable, and may lead to hostile anger and frustration. Clearly, future research is needed to replicate and further examine this latter finding.

There were several limitations to the present study. First, the study design was cross-sectional thereby strongly limiting the ability to infer with confidence direction of causality. Although we found suggestive evidence for both mediational models and there is prior evidence consistent with the findings, we cannot be confident in the present findings of either causal model. Further research using longitudinal or experimental methodologies is needed to better ascertain direction of causality. Second, the present findings rely on self-report measures, which may be prone to self-presentational demands and shared method variance confounds. Supplemental tests of common variance (Harman's single factor test in SPSS, and a common latent factor test in Mplus) suggest that shared method variance accounted for a relatively small percent of the total variance $(4-11 \%)$ in the model tests. However, future research should utilize multiple report or multimethod (e.g., physiological measures, behavioral tasks) approaches to better minimize such concerns. And third, although the present findings extend prior research findings to a relatively large and representative sample of adolescents from Spain, research from non European-based samples are needed. Such research would allow one to test the limits of the generalizability of the models to adolescents across different sociocultural contexts. Despite these limitations, the findings add to the mounting evidence on the interplay among socioemotive traits and coping styles in predicting prosocial and aggressive behaviors.

\section{Acknowledgements}

The authors greatly appreciate the assistance of Elisabeth Malonda Vidal and the cooperation of the educational centers in Valencia. Funding support was provided to Gustavo Carlo by a Visiting Scholar Fellowship from the Universitat de Valencia and by an I\&R\&D project grant (reference BSO2001-3042) of the Ministry for Science and Technology (2001-2004) to Maria Mestre.

\section{References}

Bolger, N. (1990). Coping as a personality process. A prospective study. Journal of Personality and Social Psychology, 59, 525-537. 
Bolger, N., \& Schilling, E. A. (1991). Personality and the problems of everyday life: The role of neuroticism in exposure and reactivity to daily stressors. Journal of Personality, 59, 355-386.

Bolger, N., \& Zuckerman, A. (1995). A framework for studying personality in the stress process. Journal of Personality and Social Psychology, 69, 890-902.

Bryant, B. K. (1982). An index of empathy for children and adolescents. Child Development, 53, 413-425

Buss, A. H., \& Plomin, R. (1975). A temperament theory of personality development. Oxford, England: Wiley.

Caprara, G. V., \& Pastorelli, C. (1993). Early emotional instability, prosocial behavior, and aggression: Some methodological aspects. European Journal of Personality, 7 , 19-36.

Carlo, G. (2006). Care-based and altruistically based morality. In M. Killen \& J. G. Smetana (Eds.), Handbook of moral development (pp. 551-579). Mahwah, NJ: Lawrence Erlbaum.

Carver, C. S., \& Scheier, M. F. (1994). Situational coping and coping dispositions in a stressful transaction. Journal of Personality and Social Psychology, 66(1), 184-195.

Cheng, C. (2001). Assessing coping flexibility in real-life and laboratory settings: A multimethod approach. Journal of Personality and Social Psychology, 80, 814-833.

Coie, J. D., \& Dodge, K. A. (1998). Aggression and antisocial behavior. In N. Eisenberg, W. Damon, \& N. Eisenberg (Eds.), Handbook of child psychology and personality developments (5th ed.. Social, emotional (5th ed.) (3, pp. 779-862). Hoboken, NJ, USA: Wiley.

Cole, P. M., Llera, S. J., \& Pemberton, C. K. (2009). Emotional instability, poor emotional awareness, and the development of borderline personality. Development and Psychopathology, 21, 1293-1310.

Cole, P. M., Michel, M. K., \& Teti, L. O. (1994). The development of emotion regulation and dysregulation: A clinical perspective. Monographs of the Society for Research in Child Development, 59(240), 73-100.

Compas, B. E., Connor-Smith, J. K., Saltzman, H., Thomsen, A., \& Wadsworth, M. E. (2001). Coping with stress during childhood and adolescence: Problems, progress, and potential in theory and research. Psychological Bulletin, 127(1), 87-127.

Cooper, M. L., Wood, P. K., Orcutt, H. K., \& Albino, A. (2003). Personality and the predisposition to engage in risky or problem behaviors during adolescence. Journal of Personality and Social Psychology, 84, 390-410.

Del Barrio, V., Moreno, C., \& Lopez, R. (2001). Evaluación de la aggression e inestabilidademocional en niñosespañoles y surelación con la depression. Clínica y Salud, 13, 33-50.

Derryberry, D., \& Rothbart, M. K. (1988). Arousal, affect, and attention as components of temperament. Journal of Personality and Social Psychology, 55, 958-966.

Eisenberg, N., \& Fabes, R. A. (1992). Emotion, regulation, and the development of social competence. In M. S. Clark (Ed.). Emotion and social behavior. Thousand Oaks, CA, USA: Sage, pp. 119-150.

Eisenberg, N., Fabes, R. A., \& Spinrad, T. L. (2006). Prosocial development. In Handbook of child psychology. In N. Eisenberg, W. Damon, \& R. M. Lerner (Eds.). Social, emotional and personality development (6th ed.) (3, pp. 646-718). Hoboken, NJ: Wiley.

Frydenberg, E., \& Lewis, R. (1996). A replication study of the structure of the adolescent coping scale: Multiple forms and applications of a self-report inventory in a counseling and research context. European Journal of Psychological Assessment, 12(3), 224-235.

Hoffman, M. L. (2000). Empathy and moral development: Implications for caring and justice. New York: Cambridge University Press.

Hofmann, S. G., Grossman, P., \& Hinton, D. E. (2011). Loving-kindness and compassion meditation: Potential for psychological interventions. Clinical Psychology Review, 31(7), 1126-1132.
Hu, L., \& Bentler, P. M. (1999). Cutoff criteria for fit indexes in covariance structure analysis: Conventional criteria versus new alternatives. Structural Equation Modeling, 6, 1-55.

Kliewer, W., Fearnow, M. D., \& Miller, P. A. (1996). Coping socialization in middle childhood: Tests of maternal and paternal influences. Child Development, 67(5), 2339-2357.

Koenigsberg, H. W. (2010). Affective instability: Toward an integration of neuroscience and psychological perspectives. Journal of Personality Disorders, $24,60-82$.

Lazarus, R. S., \& Folkman, S. (1984). Stress, appraisal, and coping. New York: Springer

Leech, S. L., Day, N. L., Richardson, G. A., \& Goldschmidt, L. (2003). Predictors of selfreported delinquent behavior in a sample of young adolescents. Journal of Early Adolescence, 23, 78-106.

MacKinnon, D. P., Lockwood, C. M., Hoffman, J. M., West, S. G., \& Sheets, V. (2002). A comparison of methods to test mediation and other intervening variable effects Psychological Methods, 7, 83-104.

Martino, S. C., Ellickson, P. L., Klein, D. J., McCaffrey, D., \& Edelen, M. O. (2008) Multiple trajectories of physical aggression among adolescent boys and girls. Aggressive Behavior, 34, 61-75.

Mestre, M. V., Pérez, D. E., Frías, D. \& Samper, P. (1999). Instrumentos de evaluación de la empatía. In: E Pérez Delgado \& V. Mestre (Eds.), Psicología moral y crecimiento personal (pp. 181-190). Barcelona: Ariel.

Muthén, L. K., \&Muthén, B. O. (1998-2010). Mplus User's Guide (6th ed.). Los Angeles, CA: Muthén \& Muthén.

Pastorelli, C., Barbaranelli, C., Cermak, I., Rozsa, S., \& Caprara, G. V. (1997) Measuring emotional instability, prosocial behavior, and aggression in preadolescents: A cross-national study. Personality and Individual Differences, 23, 691-703.

Pereña, J., \& Seisdedos, N. (1997). ACS. Escalas de afrontamientoparaadolescentes. Madrid: TEA.

Preacher, K. J., \& Kelley, K. (2011). Effect size measures for mediation models: Quantitative strategies for communicating indirect effects. Psychological Methods, 16, 93-115.

Pulkinnen, L., \& Pitkanen, T. (1993). Continuities in aggressive behavior from childhood to adulthood. Aggressive Behavior, 19, 249-263.

Roesch, S. C., Aldridge, A. A., Vickers, R. R., \& Helvig, L. K. (2009). Testing personalitycoping diatheses for negative and positive affect: A longitudinal evaluation. Anxiety, Stress \& Coping: An International Journal, 22(3), 263-281.

Rothbart, M. K., Ahadi, S. A., \& Hershey, K. L. (1994). Temperament and socia behavior in childhood. Merrill-Palmer Quarterly, 40, 21-39.

Samper, P., Tur, A. M., Mestre, V. V., \& Cortés, M. T. (2008). Agresividad y afrontamiento en la adolescencia.Unaperspectiva intercultural. International Journal of Psychology \& Psychological Therapy, 8(3), 431-440.

Sever, I., Guttmann, J., \& Lazar, A. (2007). Positive consequences of parental divorce among Israeli young adults: A long-term effect model. Marriage \& Family Review, 42, 7-28.

Short, J. L. Roosa, M. W. Sandler, I. N. \& Ayers, T. S. (1995). Evaluation of preventive intervention for a self-selected subpopulation of children. American Journal of Community Psychology, 23(2), 223-247.

Vollrath, M. (2001). Personality and stress. Scandinavian Journal of Psychology, 42, 335-347.

Vollrath, M., Alnaes, R., \& Torgersen, S. (1998). Coping styles predict change in personality disorders. Journal of Personality Disorders, 12(3), 198209.

Woodward, L. E., Murrell, S. A., \& Bettler, R. F. (2005). Empathy and interpersonal style: A mediational model of secondary traumatic stress symptomatology following 9/11. Journal of Aggression, Maltreatment $\mathcal{E}$ Trauma, 11(4), 1-28. 